\title{
Atopy, bronchial responsiveness, and symptoms in wheezy 3 year olds
}

\author{
Nicola M Wilson, Stephen B Phagoo, Michael Silverman
}

\begin{abstract}
Fifty children with at least one hospital admission for acute lower airway obstruction in the first 2.5 years of life were assessed at 3 years of age to determine the relationship between atopy, bronchial responsiveness, and the pattern of their symptoms. Bronchial responsiveness was measured by assessing the effect of inhaled metacholine, using the change in transcutaneous oxygen tension $\left(\mathrm{PtcO}_{2}\right)$ as an indirect measure of response. Symptom patterns were defined by the number of wheezing episodes associated with colds and the presence or absence of cough or wheeze unrelated to viral infections. Forty per cent of the children were found to be atopic by skin prick test or history. In contrast to the situation found in older children and adults, the non-atopic children had significantly greater bronchial responsiveness (lower mean concentration of methacholine causing a $20 \%$ fall in $\mathbf{P t c o}_{2}$, the $\mathbf{P C}_{20}$ ) than the atopic children and significantly more of them had an onset of respiratory symptoms in the first year of life. Cough and wheeze in the absence of colds was more frequently found in the atopic children as was the use of continuous medication. However, the number of reported acute episodes of wheeze associated with colds was the same in the two groups. The findings of the study suggest that in this hospital based group of children, acute wheeze associated with colds in the first three years of life is independent of the finding of atopy and that bronchial responsiveness in this age group may have a different pathogenesis from that in older subjects.
\end{abstract}

Recurrent acute episodic wheeze is very common in early childhood. It is usually associated with viral infections and is often described as 'post bronchiolitic' wheeze in the first two years of life. However, little is known about the natural history of wheezing and its relationship to atopy and bronchial responsiveness during the preschool period. Previous studies have usually selected a particular population of children at risk, for example, children of atopic families $^{12}$ or those who have experienced acute viral bronchiolitis in infancy. ${ }^{3-5}$ Thus the relationship between recurrent post bronchiolitic wheezing and the development of atopic asthma, characteristic of older children, remains unclear. An additional problem has been the lack of a universally accepted definition of bronchiolitis; indeed the term is used differently on each side of the Atlantic. Clinically, a young child with an episode of wheeze after bronchiolitis caused by respiratory syncytial virus and a highly atopic child with an early episode of 'asthma' may both present with an identical, discrete episode of wheezing related to a viral infection. It has been suggested that both categories of children share a common factor which induces a predisposition to wheeze in association with viral infections that is independent of atopy, but that only those who develop airway sensitisation to aeroallergens will develop asthma in later childhood. ${ }^{6}$

The division of wheezy infants into two such distinct populations is still controversial. Some workers claim that all young wheezers should be considered as deriving from the same population and that any difference between them is merely one of severity. ${ }^{7}$ Information currently available does not satisfactorily resolve this debate. A longitudinal population study of children born to atopic parents has shown a bimodal period prevalence of wheezing. Those wheezing before the age of 2 years rarely wheezed after that age, in contrast to those with an older age of onset in whom wheezing persisted and was strongly associated with atopy. ${ }^{1}$

It is important to ascertain whether or not subgroups of wheezers in fact exist as, if present, this could imply differences in underlying pathology and associated risk factors. Also, it is possible that, if prognosis and clinical outcome varies between subgroups, a different therapeutic approach, either in the short or long term, might be appropriate. Without considering various patterns of wheezing in young children separately, these important questions cannot be answered.

Therefore, in order to see if there exist subpopulations of young wheezers, which can be distinguished by the pattern of their symptoms, development of atopy or degree of bronchial responsiveness, a cohort of 50 children who had been admitted to hospital with an acute episode of lower respiratory obstruction (wheeze) during the first 2.5 years of life, was recruited. The intention was to include those with a diagnosis of bronchiolitis, recurrent post bronchiolitic wheezing, and 'wheezy bronchitis' as well as atopic children with early asthma. As part of a prospective study, these children were first seen as near to their third birthday as possible, and our findings form the basis of this report.

Subjects and methods

Children born between January 1986 and June 1987, who had been admitted to Hammersmith 
Hospital with an episode of acute lower respiratory obstruction in the first 2.5 years of life were selected from the hospital records. The following diagnoses were included: bronchiolitis, acute wheeze, wheezy bronchitis, and asthma. Recruiting to the study continued until $\mathbf{5 0}$ children had been enrolled. They were seen as near as possible to their third birthday when the following assessments were made.

\section{PERSONAL AND FAMILY HISTORY}

The age of admission and clinical details including diagnosis were obtained from the hospital notes. A detailed written questionnaire was completed by a parent. This included information about parents and siblings concerning respiratory symptoms and their relationship to viral infections, allergies, and home conditions. For the index child, details were obtained about the medical and atopic history, and about respiratory symptoms including age of onset, relationship to viral infections, and other environmental stimuli. A positive history of atopy was defined as the presence of eczema, rhinoconjunctivitis to a known allergen, reaction to animal dander, or unequivocal food intolerance. A question was specifically asked about the estimated number of acute episodes of wheezing associated with viral infections and about the presence or absence of cough or wheeze in the absence of upper respiratory infections.

\section{SKIN PRICK TESTS}

These were performed using a specially designed device which held up to eight lancets (Phazet, Pharmacia). The device allowed multiple skin prick tests to be performed simultaneously, ensuring uniform skin penetration and maximal response. ${ }^{8}$ Five lancets were used: one control, one histamine coated, and three allergen coated (Dermatophagoides pteronynissinus, cat, and timothy grass). As Phazets are not available for food allergens, an additional control lancet was placed over a drop of a wet preparation of egg extract (Merck Ltd). The maximal diameter of each skin weal was measured with a ruler after 15 minutes. The responses were read by the same observer throughout the study. A weal size of $\geqslant 2 \mathrm{~mm}$ was considered a positive response to allergen.

\section{METHACHOLINE CHALLENGE}

An interval of at least two weeks was allowed before the test after a clinical viral infection. All medication was witheld for 24 hours. The challenge was performed by administering methacholine sulphate aerosol for one minute through a Wright nebuliser using a mouth piece, with the nose clipped. The subject remained quietly seated throughout the study. The starting concentration of methacholine was $0.5 \mathrm{~g} / \mathrm{l}$ and the inhalations were repeated at five minute intervals using quadrupling dilutions up to a maximum of $32 \mathrm{~g} / \mathrm{l}$. The same nebuliser was used for each subject with airfow of $7 \cdot 5 \mathrm{l} /$ minute. The output of the nebuliser was checked at intervals between subjects to ensure constancy. After the final concentration of methacholine, the child was given nebulised salbutamol in order to facilitate rapid recovery.

The response was assessed by monitoring the fall in transcutaneous oxygen tension $\left(\mathrm{PtcO}_{2}\right)$ using a skin electrode (Kontron) attached to the chest wall and heated to $44^{\circ} \mathrm{C} .{ }^{9}$ The electrode was calibrated in air $(20.9 \mathrm{kPa})$. After application, an equilibration period of at least 20 minutes was allowed. Baseline measurements were made by taking records on the minute for eight minutes. After methacholine inhalation, a reading was taken at exactly 1,2 , and 3 minutes after each inhalation. The exact concentration of methacholine causing a $20 \%$ fall in $\mathrm{PtcO}_{2}$ $\left(\mathrm{PC}_{20}\right)$ was calculated by interpolation using the last two points on the log concentration response curve.

An informed verbal and written consent was obtained from a parent and approval for the study was obtained from the hospital ethics committee.

\section{ANALYSIS}

The significance of differences between groups was assessed using a $\chi^{2}$ test with a Yates's correction or one way analysis of variance, as appropriate. Correlations between factors were made using regression analysis. A $p$ value of $<0.05$ was considered significant.

\section{Results}

Of the 50 children, 31 were boys. Their ethnic origins were: 29 white, six from the Indian subcontinent, and 15 were Afro-Caribbean. Details of their respiratory history, including age of onset, use of prophylactic medication, frequency of attacks, duration since last wheezing episode, and presence or absence of symptoms between viral infections are shown in table 1 .

Table 1 Characteristics and pattern of lower respiratory symptoms for the group as a whole and the atopic and non-atopic children compared. Results are

\begin{tabular}{|c|c|c|c|c|c|c|c|c|c|c|c|c|}
\hline & \multirow[t]{2}{*}{ Male } & \multicolumn{3}{|c|}{$\begin{array}{l}\text { Prophylactic } \\
\text { medication }\end{array}$} & \multicolumn{2}{|c|}{$\begin{array}{l}\text { Age at index } \\
\text { admission }\end{array}$} & \multicolumn{2}{|l|}{$\begin{array}{l}\text { Admission } \\
\text { diagnosis }\end{array}$} & \multicolumn{2}{|c|}{$\begin{array}{l}\text { Age at onset } \\
\text { of wheeze } \\
\text {. }\end{array}$} & \multicolumn{2}{|c|}{$\begin{array}{l}\text { Smoking } \\
\text { mother }\end{array}$} \\
\hline & & Nil & $\begin{array}{l}\text { Inhaled } \\
\text { steroids }\end{array}$ & $\begin{array}{l}\text { Sodium } \\
\text { cromoglycate }\end{array}$ & $<1$ year & $\geqslant 1$ year & Bronchiolitis & $\begin{array}{l}\text { Asthma, } \\
\text { wheeze, or } \\
\text { wheezy } \\
\text { bronchitis }\end{array}$ & $<1$ year & $\geqslant 1$ year & Yes & No \\
\hline $\begin{array}{l}\text { Atopic } \\
(n=20)\end{array}$ & $13(65)$ & $12(60)$ & $5(25)$ & $3(15)$ & $6(30)$ & $14(70)$ & $11(55)$ & $9(47)$ & $8(40)$ & $12(60)$ & $5(25)$ & $15(75)$ \\
\hline$\underset{(\mathbf{n}=30)}{\text { Non-atopic }}$ & $18(60)$ & $29(97)$ & $1(3)$ & $0(0)$ & $17(57)$ & $13(43)$ & $11(37)$ & $19(63)$ & $23(77)$ & $7(23)$ & $10(33)$ & $20(66)$ \\
\hline Total & $31(62)$ & $41(82)$ & $6(12)$ & $3(6)$ & $23(46)$ & $27(54)$ & $22(44)$ & $31(62)$ & $19(38)$ & $15(30)$ & $15(30)$ & $35(70)$ \\
\hline
\end{tabular}

Significance of difference between atopic and non-atopic children by $\chi^{2}$ test: ${ }^{*} \mathrm{p}<0 \cdot 04,{ }^{* *} \mathrm{p}=0 \cdot 002,{ }^{* * *} \mathrm{p}<0 \cdot 001$ 
Table 2 Geometric mean methacholine $P_{20}$ in the 35 children who performed methacholine challenge. The results are shown for groups of subjects, divided according to characteristics and symptom patterns

\begin{tabular}{|c|c|c|c|c|c|c|c|c|c|c|c|c|}
\hline & \multicolumn{2}{|l|}{$\begin{array}{l}\text { Admission } \\
\text { diagnosis }\end{array}$} & \multirow[t]{2}{*}{ Atopic } & \multirow[t]{2}{*}{ Non-atopic } & \multicolumn{2}{|c|}{$\begin{array}{l}\text { Interval since last } \\
\text { symptom (months) }\end{array}$} & \multicolumn{2}{|c|}{$\begin{array}{l}\text { Reported number } \\
\text { of attacks }\end{array}$} & \multicolumn{2}{|c|}{$\begin{array}{l}\text { Cough/wheeze } \\
\text { between colds }\end{array}$} & \multicolumn{2}{|c|}{$\begin{array}{l}\text { Smoking } \\
\text { mother }\end{array}$} \\
\hline & Bronchiolitis & $\begin{array}{l}\text { Asthma, } \\
\text { wheeze, or } \\
\text { wheezy } \\
\text { bronchitis }\end{array}$ & & & $<6$ & $\geqslant 6$ & $1-6$ & $>6$ & Yes & No & Yes & No \\
\hline $\begin{array}{l}\text { No of children } \\
\text { Methacholine } \mathrm{PC}_{20}\end{array}$ & $\begin{array}{l}17 \\
4 \cdot 3\end{array}$ & $\begin{array}{l}18 \\
4 \cdot 3\end{array}$ & $\begin{array}{l}17 \\
6 \cdot 7\end{array}$ & $\begin{array}{l}18 \\
2 \cdot 8\end{array}$ & $\begin{array}{l}20 \\
4 \cdot 8\end{array}$ & $\begin{array}{l}15 \\
4 \cdot 8\end{array}$ & $\begin{array}{l}12 \\
5 \cdot 1\end{array}$ & $\begin{array}{l}22 \\
4 \cdot 1\end{array}$ & $\begin{array}{l}21 \\
5 \cdot 1\end{array}$ & $\begin{array}{l}14 \\
3 \cdot 7\end{array}$ & $\begin{array}{l}9 \\
4 \cdot 3\end{array}$ & $\begin{array}{l}26 \\
4 \cdot 3\end{array}$ \\
\hline
\end{tabular}

NS=not significant.

ASSESSMENT OF ATOPY

A skin weal response to histamine of $\geqslant 2 \mathrm{~mm}$ was found in all children. None showed a response to the control of more than $1 \mathrm{~mm}$. Eighteen children had a positive $(\geqslant 2 \mathrm{~mm})$ skin weal response to at least one allergen and in all except three of these children there was a definite atopic history. Two children with an atopic history had negative skin prick tests. Using the criteria of either a skin response of $\geqslant 2$ $\mathrm{mm}$ to at least one allergen or a positive atopic history, 20 children were considered atopic.

\section{RELATIONSHIP OF ATOPY TO PATTERN OF} RESPIRATORY SYMPTOMS (TABLE 1)

There was no difference in the prevalence of atopy between the sexes or between those with an admission diagnosis of bronchiolitis or other types of wheezing (asthma, wheeze, or wheezy bronchitis). There was no difference in the number of acute wheezing episodes associated with presumed viral infection reported by the atopic and the non-atopic children. Significantly more atopic children had symptoms between viral infections $(p=0.04)$ and were using continuous prophylactic medication $(p<0.001)$. Non-atopic children were more likely to have had their first lower respiratory symptom under 1 year of age $(p=0.02)$ and more had been admitted to hospital under 1 year of age $(p=0 \cdot 04)$.

\section{METHACHOLINE RESPONSIVENESS}

A methacholine challenge was successfully completed by 35 of the 50 children. One parent refused permission, there was a technical problem with one test, and the remaining 13 children were unable to cooperate.

In all the completed challenges, a $\mathbf{P C}_{20}$ of less than $32 \mathrm{~g} / \mathrm{l}$ (the highest concentration used) was obtained. There was no significant difference in the geometric mean $\mathrm{PC}_{20}$ between boys and girls

number (\%)

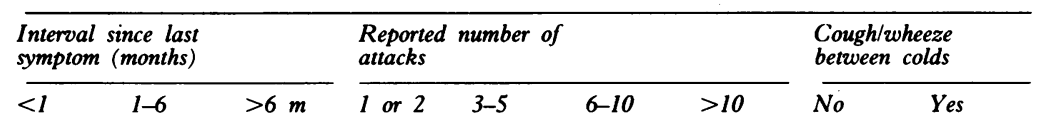

\begin{tabular}{rrrllllll}
\hline $12(60)$ & $5(25)$ & $3(15)$ & $1(5)$ & $3(15)$ & $3(15)$ & $13(65)$ & $6(30)$ & $14(70)$ \\
$11(37)$ & $6(20)$ & $13(43)$ & $6(20)$ & $4(15)$ & $8(27)$ & $12(40)$ & $19(63)$ & $11(37)$ \\
$23(46)$ & $11(22)$ & $16(32)$ & $7(14)$ & $7(14)$ & $11(22)$ & $25(50)$ & $25(50)$ & $25(50)$ \\
\hline
\end{tabular}

(table 2). Nor was there a difference in $\mathrm{PC}_{20}$ according to the season or the month of testing. The geometric mean $\mathrm{PC}_{20}$ was significantly lower $(p=0.01)$ in non-atopic children than the atopic (table 2). There was no significant association between $\mathrm{PC}_{20}$ and (a) the presence or absence of symptoms between acute viral episodes, (b) the presence of symptoms within the preceding six months, or (c) maternal smoking (table 2).

\section{Discussion}

This study has considered the outcome, at 3 years of age, of a hospital based cohort of children with a history of wheeze. It differs from most previous similar studies in that the children were not preselected according to diagnosis or atopic family history. By the age of 3 years, $40 \%$ of the children were considered to show evidence of atopic sensitisation. Further children within the group are likely to become manifestly atopic as they grow older as atopic features increase with age. ${ }^{19}$ It is not known whether or not atopy generated symptoms can precede skin sensitisation in this age group. The skin tests were performed by a well validated $\operatorname{method}^{8}$ so technical problems are not likely to account for negative skin test results. In older children, a skin weal diameter of at least $4 \mathrm{~mm}$ has been recommended to describe a clinically significant atopic response. ${ }^{10}$ Skin responses increase with age during childhood, ${ }^{11} 12$ and in two of this group we were unable to obtain a histamine response greater than $2 \mathrm{~mm}$ despite repeated attempts. As there was a very close association between a positive skin prick test and an atopic history using this cut off point, a $2 \mathrm{~mm}$ weal is likely to be relevant in this age group, using allergen coated lancets. Two children with a positive atopic history had negative skin prick tests. In one of them the atopy was based solely on a history of eczema, which, it has been suggested, may be confused with seborrhoeic dermatitis. ${ }^{1}$ It is possible that this one child was wrongly classified.

In this study of 3 year olds, a difference in the pattern of wheezing symptoms was discernable between the atopic and non-atopic children. The latter were more likely to have experienced the onset of symptoms within the first year of life while the atopic children more frequently reported symptoms between acute viral episodes. Chronic, as opposed to acute intermittent asthma, was also found by Zimmerman and colleagues to be more characteristic of highly atopic children who, like the atopic children in 
this study, were more likely to be taking continuous prophylactic medication. ${ }^{13}$ This difference in medication between atopic and nonatopic children could arise because those with a family history of atopy are more likely to be given prophylaxis. In the present study, both groups of children showed a tendency to experience recurrent episodic wheeze in association with clinical viral infections but the reported numbers of episodes did not differ between the two groups. This implies, as has been previously suggested, that in this age group, the tendency to wheeze in response to viral infections is independent of atopy. ${ }^{1614}$ Only $15 \%$ of the atopic children had been symptom free for more than six months compared with $43 \%$ of the nonatopic children. Although the differences were not statistically significant, this could indicate a trend that may become apparent with increasing age.

Bronchial responsiveness has not previously been assessed in a cohort of 3 year old children. As children in this age group are unable to cooperate with repeated measurements of lung function, we had to resort to using changes in $\mathrm{PtCO}_{2}$ as an indirect measure of bronchoconstriction. Mochizuki et al found a good correlation between the threshold dose of methacholine as measured by changes in respiratory resistance and that measured by $\mathrm{PtcO}_{2}$ in older and sedated preschool children. ${ }^{15}$ In older subjects we found no significant differences in the methacholine concentration causing a $20 \%$ fall in $\mathrm{PtcO}_{2}$ and that producing a $40 \%$ increase in respiratory resistance. ${ }^{9}$ In a small number of normal adult subjects, the repeatability of the $\mathrm{PC}_{20}$ values assessed by a fall in $\mathrm{PtcO}_{2}$ was within one doubling dilution of methacholine, and similar to that calculated simultaneously using respiratory resistance. ${ }^{9}$ It is not clear from the present results whether or not bronchial responsiveness in this group of children as a whole deviated from that of children without a history of wheezing. As population data were not available only a between group comparison was possible. Our finding that the non-atopic children were significantly more responsive to inhaled methacholine than the atopic children is the reverse of the situation found in older children and adults. ${ }^{1016} 17$ Recent viral infections and month of testing are unlikely to account for the difference as neither the interval since the last symptom nor the month of test were related to the $\mathrm{PC}_{20}$. It could be argued that the reduced bronchial responsiveness in the atopic children was due to their increased use of topical steroid treatment (table 2). However, in adult asthmatic subjects the bronchial responsiveness was greatest in those taking regular inhaled steroids. ${ }^{18}$ Variations in delivered concentration of methacholine to the lung due to air entrainment could not explain the difference as both groups were the same age. ${ }^{19}$

It is a possibility that in young children the relationship between bronchial responsiveness, respiratory symptoms, and atopy depends upon the population selected. For example, in a prospective study of infants of atopic parents, atopic sensitisation in infancy strongly predicted both appreciable hyper-responsiveness, when it was first assessed at 7 years, and an increased tendency to wheeze. ${ }^{2}$ In contrast, in a follow up study of children with bronchiolitis in infancy assessed when aged 5-6 years, there was no relationship between either bronchial responsiveness and current wheezing (point prevalence $71 \%$ ) or bronchial responsiveness and a family history of atopy. ${ }^{5}$

This apparent discrepancy between the two populations, which was also noted in older children by Clifford and colleagues, ${ }^{11}$ might be explained by the findings of Crane and colleagues who performed a population cross sectional study of Tokelauan immigrant children aged between 5 and 13 years. ${ }^{20}$ It was found that bronchial responsiveness was similar in atopic and non-atopic children of 5-6 years but became increasingly discrepant with age. The histamine $\mathrm{PC}_{20}$ increased appreciably between the age bands 5-6 and 7-8 years in atopic children, but in contrast it gradually declined with age in the non-atopic children. This suggests that the pathogenesis of bronchial responsiveness may be different in atopic and non-atopic children. Its relationship to atopy will therefore depend on the population selected for study and the age of the child.

In the present study, bronchial responsiveness was assessed at a young age and the high level of responsiveness in non-atopic children could have reflected relatively smaller airways. We had hoped to include a measure of respiratory resistance using the forced oscillation technique. Unfortunately the majority of the children were unable to cooperate, so no direct measurement of airway function is available. Martinez and coworkers, assessing babies before their first respiratory symptom, found that those who subsequently developed lower respiratory symptoms with viral infections had the poorest lung function. ${ }^{21}$ The association with preceding poor lung function was most noticeable in those in whom wheezing persisted into the second and third years of life.

Respiratory symptoms in very young children are associated with maternal or passive smoking. ${ }^{22}$ In our study smoking in parents was not significantly related to symptoms or methacholine $\mathrm{PC}_{20}$. As a surprisingly small number $(30 \%)$ of parents admitted to being smokers (table 1) and as no objective measurements, such as cotinine concentrations were made, these findings may not be reliable.

The outcome of children said to have bronchiolitis during their index admission was no different from those given the diagnosis of asthma, acute wheeze, or wheezy bronchitis. Changing the criteria for a diagnosis of 'bronchiolitis' by only including those admitted under 9 months of age with appreciable chest hyperinflation and predominant fine crepitations $(n=15)$ made no difference to outcome in terms of the number of reported subsequent acute wheezy episodes or the development of atopy.

This observation is in agreement with previous studies that have not found any difference in outcome between infants admitted with a variety of lower respiratory illnesses including bronchiolitis, both with and without respiratory 
syncytial virus isolation. ${ }^{24}$ Therefore the term bronchiolitis would seem to have no significant epidemiological meaning, although it may be considered to constitute a definite clinical syndrome. The term post bronchiolitic wheeze may therefore be confusing as a description of early episodic wheezing as it implies a causal role between the first and subsequent illnesses.

The findings of this study are compatible with the proposal that the varying interaction of three factors-bronchial hyper-responsiveness, atopy, and an increased susceptibility to lower respiratory manifestation of viral infectionsgives rise to the differing patterns of asthma seen during childhood. ${ }^{6}$ The changing pattern of wheezing during early childhood could be explained by this hypothesis as follows. The early development of lower airway obstruction in relation to viral infections could occur in those with a combination of poor airway function (a probable determinant of increased bronchial responsiveness) and a particular susceptibility to viral infections. With age the size of the airways increases and viral infections become less frequent, so that the tendency to wheeze in response to viral infections will diminish, unless bronchial responsiveness is perpetuated by airway inflammation associated with atopy.

In addition, the results of this study suggest that although the number of acute wheezing episodes related to clinical viral infections in the first three years of life is independent of atopy, the tendency to wheeze between viral infections was associated with atopy. The finding of increased bronchial responsiveness in the nonatopic 3 year olds contrasts with the reverse situation reported in older subjects with asthma and lends weight to the idea of a different pathogenesis for bronchial responsiveness in the two age groups. By 3 years, however, it was not possible to define two distinct populations of wheezers, although differences were seen between the atopic and the non-atopic children. There were, however, sufficient differences to encourage other workers, with perhaps larger community based populations, to consider the possibility of a differing pathogenesis between acute episodic wheezing in association with viral infections and the more chronic asthma characteristic of older children. As the children in the present study are followed up as part of an ongoing prospective study it should become clear by their outcome whether the evidence supports the view that all childhood wheezers arise from a single population ${ }^{7}$ or alternatively, as proposed on theoretical grounds ${ }^{6}$ and by indications from a prospective study, ${ }^{1}$ that two populations exist which can only be differen- tiated by the development of atopy with the passage of time.

We are grateful to the National Asthma Campaign for their support of this study.

1 Sporik R, Holgate ST, Cogswell JJ. The natural history of asthma in childhood: a birth cohort study. Arch Dis Child $1991 ; 66: 1050-3$

2 Van Asperen PP, Kemp AS, Mukhi A. Atopy in infancy predicts the severity of bronchial hyperresponsiveness in

later childhood. F Allergy Clin Immunol 1990;85:750-5.
Pullan CR, Hey EN. Wheezing asthma and pulmonary dysfunction 10 years after infection with respiratory syncytial virus. $B M F$ 1982;284:1665-9

4 Milner AD. Acute bronchiolitis in infancy: treatment and prognosis. Thorax 1989;44:1-5.

5. Sly PD, Hibbert ME. Childhood asthma following hospitalization with acute viral bronchiolitis in infancy. Pediat Pulmonol 1989;7:153-8.

6 Wilson NM. Wheezy bronchitis revisited. Arch Dis Child 1989;64:1191-9.

7 Williams H, McNicholl KN. Prevalence, natural history and relationship of wheezy bronchitis and asthma in children. An epidemiological study. $B M \mathcal{F}$ 1969;iv:321-5.

8 Phagoo SB, Wilson NM, Silverman M. Skin prick testing using allergen coated lancets: a comparison between a multiple lancet device and a single lancet applied with multiple lancet device and a single lancet applied

9 Warying pressure. Clin Exp Allergy 1991;21:589-92. oxygen tension, arterial oxygen saturation and respiratory resistance to assess the response to inhaled methacholine in resistance to assess the response to inhaled methacholine
children and normal adults. Thorax 1991;46:433-7.

10 Peat JK, Salome CM, Woolcock AJ. Longitudinal changes in atopy during a 4 year period: relation to bronchial hyperresponsiveness and respiratory symptoms in a population sample of Australian schoolchildren. $\mathcal{F}$ Allergy Clin Immunol 1990;85:65-74.

11 Clifford RD, Howell JB, Radford M, Holgate ST. Association between respiratory symptoms, bronchial response to methacholine and atopy in two age groups of schoolchildren. Arch Dis Child 1989;64:1133-9.

12 Kassa S, Brociek W, Manderscheid JC, Michel FB, Bousque J. Skin reactivity to histamine from infancy to old age. $\underset{f}{ }$ Allergy Clin Immunol 1987;80:711-6.

13 Zimmerman B, Fearny S, Reisman J, et al. Allergy in asthma 1. The dose relationship of allergy to severity of childhood asthma. F Allergy Clin Immunol 1988;81:63-70.

14 Matsula A, Ziegler T, Ranskaren O, Vanto T, Koivikko A Halonen P. Recurrent wheezy bronchitis and viral
tory infections. Arch Dis Child 1991;66:124-9.

15 Mochizuki H, Mitsuhashi M, Tokayama K, Tajima K, Morihawa A, Kurome T. A new method of estimating bronchial hyperresponsiveness in younger children with asthma. Ann Allergy 1988;60:103-6.

16 Witt C, Stackey MS, Woolcock AJ, Dawkins RL. Positive allergy prick tests associated with bronchial histamine responsiveness in an unselected population. $\mathcal{F}$ Allergy Clin Immunol 1986;77:698-702.

17 Peat JK, Salome CM, Sedgwick CS, Kerrebijn J, Woolcock AJ. A prospective study of bronchial hyperresponsivenes and respiratory symptoms in a population of Australian schoolchildren. Clin Exp Allergy 1989;19:299-306.

18 Juniper EF, Frith PA, Hargreaves FE. Airway hyperresponsiveness to histamine and methacholine: relationship to minimum treatment to control symptoms of asthma. Thorax 1981;36:575-9.

19 Collis GG, Cole CH, LeSouef PN. Dilution of nebulised aerosols by air entrainment in children. Lancet 1990;336: aerosols $341-3$.

20 Crane J, O'Donnell TV, Waite DA. The relationship between atopy, bronchial hyperresponsiveness and a family
history of asthma. A cross sectional study of migrant history of asthma. A cross sectional study of migrant
Tokelauan children in New Zealand. $f$ Allergy Clin Tokelauan children in
Immunol $1989 ; 84: 768-72$.

21 Martinez FD, Morgan WJ, Wright AL, Holbert C, Taussig L. Initial airway function is a risk factor for recurrent wheezing respiratory illnesses during the first 3 years of life. Am Rev Respir Dis 1991;143:312-6.

22 Bisgaard H, Dalgaard P, Nybol J. Risk factors for wheezing during infancy. Acta Paediatr Scand 1987;76:719-26.

23 Wright AL, Holberg C, Martinez FD, Taussig LM and Group Health Medical Associates. Relationship of parental smoking to wheezing and nonwheezing lower respiratory tract illnesses in infancy. $\mathcal{F}$ Pediatr 1991;118:207-14.

24 Mok JYQ, Simpson H. Outcome for acute bronchitis, bronchiolitis and pneumonia in infancy. Arch Dis Child 1984;59:306-9. 